\title{
Penggunaan Jajan dalam Upacara Mesabatan Biu Pada Tradisi Achi Ketiga di Desa Tenganan Dauh Tukad Karangasem (Kajian Teologi Hindu) \\ Oleh
}

Ni Made Yuliani

\begin{abstract}
The use of jajan in the masabatan biu ceremony in achi katiga tradition in the village of Tenganan Dauh Tukad Karangasem is closely related to the natural conditions of the area. Considering that the nature is rich with natural resource to be used as a complement in the masabatan biu ceremony. The achi katiga tradition is part of culture. The implementation of the achi katiga tradition contains noble values inherited by the ancestors. These values certainly need to be practiced by the community so that they can be understood and developed by the community.

The use of jajan at the masabatan biu ceremony can be used in selection of saye, the communication of this organization helps in the selection process. Selection of Saye is the selection of candidates for the leadership of Sekaa Teruna Dukuh Mengku The uniqueness of the selection of Saye is that not all members can become prospective leaders. So that in this background a problem statement can be drawn, namely what is the shape of the jajan symbol made by roban in the implementation of the Aci katiga Tradition? What is the function of the Achintya Jajan symbol made by roban in the implementation of the Aci katiga Tradition? What is the meaning of the jajan symbol made by roban in the implementation of the Aci katiga Tradition?

The three formulations of this problem are dissected using Religious Theory is one of the most complex and evolving elements in various places in the world. According to Koentjaraningrat (1980: 228-229) that if someone does something in the world, then there will be four main elements of religion in general, namely: (1). (2) a system of belief or human images about the shape of the world, nature, the unseen, life, death, etc .; (3) a system of implementation related to the world; and (4) community groups or social units that conceptualize and revive religion and the system of religious ceremonies. The use of Symbol Theory to reveal the meaning of the symbol of the use of jajan in the ceremony of the masabatan biu to the Achi katiga tradition. Etymologically, symbols or symbols are derived from the Greek word " syim-ballein " which means throwing together (objects, deeds) openness of ideas. Perception theory is the core of communication, whereas interpretation (interpretation) is the core of perception, which is identical to the decoding in the persepni process of the symbol's meaning in the use of jajan in the ceremony of the mesabatan biu in the Achi katiga tradition.
\end{abstract}

The method of data have been used is information, interviews, and documentation. Observation of the analyze, observations Interviews are carried out by constructing people, events, activities, organizations, motivations, feelings, etc. that are carried out by two parties, namely the interviewer (interviewer) who asks questions with the person interviewed (interviewed).

Keywords: use jaja, Masabatan Biu, Achi Katiga

\section{Pendahuluan}

\subsection{Latar Belakang Masalah}

Agama Hindu dan budaya Bali, menyatu padu tidak dapat dipisahkan satu dengan yang lainnya. Banyak pula pakar mengatakan, antara Agama Hindu dan budaya Bali bersinergi sedemikian rupa. Saling memperkuat dan saling memberikan sumbangan yang tidak dapat dipisahkan. Agama Hindu yang semua ajarannya bersumber dari Veda, memberi nafas hidup dan pencerahan terhadap budaya Bali.

Pengaruh Agama Hindu terhadap kebudayaan Bali khususnya dan masyarakat Indonesia pada umumnya masih tampak sangat besar. Bagi kehidupan masyarakat Bali, Agama Hindu sejak dahulu hingga kini tampak sangat dominan dan memberi warna budaya di daerah ini. 
Menurut Titib (2007). Sinergi Agama Hindu dan budaya Bali telah tampak sejak masa prasejarah Bali. Ini tampak pada banyaknya peninggalan yang diwarisi nenek moyang pada generasi masa kini. Oleh karena itulah, setiap kegian pelaksanaan tradisi selalu bernafaskan ajaran Agama Hindu.

Tradisi yang diwariskan nenek moyang ini selalu disertai dengan berbagai kegiatan upakara yang sarat makna. Inilah salah satu pelaksanaan tradisi tetap berlanjut dan berkesinambungan. Di ujung Timur pulau Bali yaitu di Kabupaten Karangasem, salah satu dari sembilan kabupaten/ kota di Provinsi Bali memiliki banyak keunikan tradisinya. Selain Karangasem dikenal dengan keindahan objek wisatanya, Karangasem juga dikenal dengan keunikan tradisi agama/ budayanya. Salah satunya di desa Adat Tenganan Dauh Tukad, ada tradisi yang diselenggarakan sekali setiap tahunnya. Tradisi ini tepatnya dilaksanakan pada sasih Ketiga (menurut kalender khusus desa Tenganan) yang lazim disebut Aci Ketiga oleh masyarakat Tenganan. Namun ada beberapa hal yang menarik, yang memerlukan pembicaraan serius tentang konsekuensi tradisi tersebut, yaitu sebagai berikut. Memandang sumber yang kurang kompeten, dan kurang adanya literatur mengenai tradisi masyarakat Tenganan, membuat proses berjalannya tradisi bagi masyarakat, didasari dengan istilah gugun tuwon. Akibat dari hal tersebut, banyak dari kalangan remaja yang khusus mengempon Aci Ketiga di Bale Agung (teruna adat) menjadi pelaku tradisi yang tanpa mengerti benar maksud maupun tujuan dari berlangsungnya tradisi tersebut. Tradisi Aci Ketiga di desa Adat Tenganan Dauh Tukad tersebut tergolong salah satu tradisi yang unik. Karena berbeda dengan tradisi di tempat lain. Mereka mengharapkan adanya literatur yang kompeten, hingga pelaku tradisi yaitu Truna Adat akan dapat memahami makna sesungguhnya mengenai tradisi Aci Ketiga tersebut. Tradisi Achi Ketiga ini dimeriahkan dengan kegiatan mesabatan biu. Kegiatan mesabatan biu dalam tradisi Aci Ketiga adalah kegiatan yang paling mencolok. Saking mencoloknya hingga kegiatan mesabatan biu dijadikan nama tradisi tersebut.
Kegiatan mesabatan biu, ini lebih dikenal dengan perang pisang. Tradisi Aci Ketiga yang makin dikenal dengan perang pisang ini terdapat di Desa Tenganan Daud Tukad Kecamatan Manggis Kabupaten Karangasem.

Tradisi Aci Ketiga yang dilaksanakan, dalam rangka memilih ketua dan wakil ketua kelompok pemuda di desa tersebut. Tradisi Aci Ketiga juga merupakan aksi penggalian dana dan pemilihan calon pemimpin, dalam organisasi Teruna Adat. Dana yang terkumpul tersebut untuk mendukung pendanaan saat Usabha Sambah pada sasih Kelima. Selanjutnya sebagai ajang pemilihan calon pemimpin yang dikehendaki organisasi Teruna Adat. Tidak ada peraturan yang pasti saat mesabatan biu dalam tradisi ini. Oleh karena itu, tidak jarang terjadi perkelahian sengit, hingga meneteskan darah dari anggota, maupun dari dua orang yaitu saye dan penampih tersebut. Namun setelah berakhirnya perang tersebut, dilanjutkan dengan acara megibung yaitu makan bersama seluruh anggota teruna adat, tidak terkecuali Saye dan Penampih tadi. Mesabatan biu atau Perang pisang ini merupakan ajang asah mental, maupun emosi bagi bakal calon pemimpin nantinya.

Kegiatan selanjutnya yaitu Penampahan, Sakaa Teruna Adat memotong babi yang nantinya dijadikan kelengkapan upakara yadnya. Nyacah Ulu-Ulu, masih lanjutan dari proses penampahan sebelumnya. Kegiatan pun dilanjutkan dengan Ngalang pertama yaitu Sekaa Teruna Adat, memetik hasil bumi seperti sayur-mayur, daun kelapa, buah kelapa, dan pisang, di areal desa. Ngalang kedua dilakukan lagi pada hari berikutnya sebelum prosesi mesabatan biu dilaksanakan.

Tradisi Aci Ketiga ini, banyak menarik minat pelaku wisatawan, para jurnalis dan peneliti. Baik dari dalam maupun dari luar negeri. Tradisi ini belum ada yang menulis atau meneliti mengenai roban atau para ibu yang membantu persiapan upakara yadnya. Terutama pada pembuatan berbagai macam jajan untuk dijadikan upacara yadnya dalam pelaksanaan Tradisi Aci Ketiga.

Aneka jajan yang dibuat roban ini memiliki kekayaan aneka ragam bentuk dan fungsi sehingga 
juga memiliki kekayaan makna yang penting dalam rangka pencerahan dan pendakian spiritual dalam pelaksanaan Tradisi Aci Ketiga. Hingga dapatlah ditarik rumusan masalah sebagai berikut;

\section{Bentuk, Fungsi, dan Makna Simbol Jajan Yang Dibuat Roban Dalam Pelaksanaan Tradisi Aci Ketiga}

Tradisi Perang pisang atau mesabatan biu di Tenganan Dauh Tukad ini digelar di pelataran pura Bale Agung, dalam rangka pelantikan ketua saye dan wakil ketua pemuda setempat atau disebut penampih. Upacara mesabatan biu dalam tradisi aci ketiga ini dimulai setelah ada aba-aba dari kelian adat Tenganan Daud Tukad. Aba-aba inilah pertanda perang dimulai, para pemuda dengan langkah setengah berlari menuju pertengahan jalan antara pura dan ujung jalan, dan di tempat inilah perang di mulai. Dua pemuda yang menjadi sasaran perang dan diperbolehkan untuk melawan tentu akan kewalahan karena perang yang tak seimbang, namun demikian kaki mereka terus melangkah menuju pura, karena mereka tidak boleh berhenti, apalagi sampai jatuh. Kalau hal itu terjadi mereka akan dianggap gagal dan tidak pantas menjadi pemimpin. Tujuan adanya pemilihan pemimpin dengan ritual mesabatan biu atau perang pisang ini untuk mencari pemimpin yang kredibel, kuat mental, dan fisik menghadapi persoalan yang semakin komplek.

\subsection{Bentuk Dan Jenis Jajan}

Selain sarana-sarana yang telah disebutkan ada pula sarana lainnya untuk melengkapi prosesi pemilihan saye tersebut. Adapun jenis jajan yang dipergunakan ada dua yaitu jenis jajan gegantungan dan jenis jajan banten. Jajan yang dipergunakan untuk gegantungan adalah begina, dodol, jaja kambing-kambingan, kemplongkemplongan, kedis-kedisan/siap-siapan, jaja cacalan roda kereta, jaja kaliadrem. Jenis jajan ini semua dirangkai sedemikian rupa untuk menghiyas seluruh bale, yaitu pura Bale agung, dan Bale sekitarnya tempat upacara mesabatan biu tersebut.
Seke truna mengumpulkan dan merangkai jajan yang akan dipergunakan untuk melengkapi kegiatan Achi Ketiga pada Tradisi Mesabatan Biu yang akan berlangsung. Adapun jajan yang dikumpulkan tersebut ada beberapa jenis seperti jajan dadalan/begina/renggina, jajan dodol, jajan satuh, jajan gegorengan, dan jajan cacalan. Selain jajan yang dikumpulkan seke truna untuk melengkapi kegiatan pemilihan saye pada achi ketiga berupa daun beringin dan buah-buahan yang diperoleh dari kebun warga Tenganan Dauh Tukad. Semua perlengkapan yang berhasil dikumpulkan tersebut diletakkan dekat dengan pusat kegiatan yaitu di Bale Agung.

Usai menyiapkan bahan yang dilaksanakan seke truna, maka bagian pembuatan jaja dilakukan oleh Roban. Roban adalah ibu-ibu yang memiliki putra sebagai seke truna Dukuh Mengku. Kalau seorang ibu yang tidak memiliki putra yang sudah menjadi seke truna maka dia tidak boleh menjadi roban. Roban inilah yang membuat jajan yang dipakai saye untuk menghiyas Bale Agung. Jajan yang diperlukan saye ini dibuat oleh roban pada lima dan tiga hari sebelum tradisi mesabatan biu dilaksanakan. Adapun jajan yang dibuat roban adalah jajan begina/dadalan yang berbentuk lingkaran, segi empat berwarna putih atau tanpa gula merah. Jajan kaliadrem berbentuk segitiga yang memiliki lubang ditengahnya. Jajan yang paling unik adalah jajan gegorengan yang berbentuk kambing-kambingan, kemplongkemplongan, siap-siapan, yaitu jajan yang terbuat dari tepung lalu dibentuk seperti kambing, boneka, ayam, dan bentuk binatang lainnya. Jajan ini di goreng hingga disebut jajan gegorengan. Selain yang telah disebutkan itu jajan yang dipersiapkan oleh Roban adalah jajan satuh, dodol, dan jajan cacalan. Semua jajan ini dipergunakan untuk banten dan hiyasan Bale Agung, Bale Perantenan, bale kulkul, dan Bale peyadnya.

Adapun bentuk jajan-jajan tersebut adalah berbentuk lingkaran atau bulat yang melambangkan hulu atau atas, sedangkan jajan yang berbentuk segi empat atau persegi empat menyimbulkan tubuh atau membadan, sedangkan jajan yang berbentuk segi tiga disebut dasar atau 
simbul kesuburan. (Wawancara Fuji, 5 Maret 2017). Simbol jajan inilah yang disiapkan oleh para ibu atau Roban untuk melengakapi upacara tradisi Aci Ketika Mesabatan Biu.

Jajan cacalan selain yang berbentuk roda kereta juga dibuat berbagai bentuk untuk keperluan banten bebangkit yang dihaturkan di Gedong Bale Agung. Jajan cacalan ini banyak bentuknya dan namanya pula semuanya itu untuk tetandingan banten Bebangkit. Jajan cacalan yang disebut yaitu ancak dan buncul khusus dibuat hanya untuk rangkaian banten bebangkit. Jajan cacalan ancak ini memiliki bentuk menyerupai pohon ancak dengan dilengkapi daun buah bunga dan batangnya. Sedangkan jajan cacalan buncul bentuknya menyerupai badan manusia lengkap dengan kepala dan badan yang berwarna putih.

Adapun kelengakapan kepalanya dengan rambut berwarna hitam, demikian pula alis dan matanya. Badan jajan cacalan buncul ini tidak dilengkapi dengan tangan dan kaki. Kedua jajan cacalan ini yaitu ancak dan buncul sebagai jajan pertama yang diletakkan dalam rangakaian banten bebangkit. Bentuk jajan cacalan andong dan gempelan ini adalah jajan yang selanjutnya sebagai pelengkap banten bebangkit. Pada jajan ini merupakan pasangan yang harus dipasangkan satu dengan lainnya hingga disebut gempelan/ pasangan. Kedua jajan ini diletakkan pada bagian kedua. Bentuknya seperti bunga, daun, batang dengan warna putih, hitam, hijau, merah muda, dan kuning.

Jajan cacalan sugih rendah yang memiliki warna sangat menarik yaitu putih, kuning, hijau, merah muda, dan hitam. Bentuk jajan ini seperti mangkok yang berhiyaskan bentuk pita pada lingkaran mangkoknya.

Jajan cacalan jukung nunggal dan jajan cacalan peteng lemah yang saling berkaitan meskipun jajan ini bukan gempelan/kelompoknya. Jajan ini bentuknya pun sangat bertentangan, jukung nunggal dominan warnanya putih dan memanjang, sedangkan peteng lemah bentuknya melingkar warna yang dipergunakan hitam berarti peteng/malam atau gelap dan putih warna lemah berarti terang atau siang. Pemberian warna pada jajan ini langsung menempel menjadi satu. Lambang ini juga dianggap kelompok lambang dualisme dua yang berbeda tetapi saling diperlukan karena bersinergi bukan bertentangan.

Jajan cacalan orti ketemu yang melambangkan dualisme yang berarti pembicaraan yang telah disepakati. Hingga dualisme yang terkandung di dalam jajan tersebut telah menjelaskan makna persetujuan dan kesepakatan dari suatu pembicaraan. Demikian pula menjelaskan perbedaan yang saling memerlukan yaitu segara gunung. Jajan cacalan ini juga bentuk simbul dari dualisme yang terjadi di alam semesta ini. Meskipun menunjukkan perbedaan namun perbedaan yang harmoni yang saling berketergantungan dan saling melengkapi. Itulah dualisme yang ingin dijelaskan di dalam pembuatan jajan cacalan tersebut, ini harus ada dan akan membuat alam ini menjadi terus berputar, jajan cacalan penyuwud yang terakhir di letakkan disaat merangkai atau metanding banten bebangkit. Jajan cacalan ini merupakan keseluruhan jajan cacalan yang dirangkai sesuai gempelan pelengkapnya dan disatukan dengan jajan lainnya serta bahan pelengkap lainnya dan pada akhirnya yang menjadi banten bebangkit. (wawancara Fuji 6 Maret 2017). Karena bentukbentuk jajan tersebut memiliki makna yang sakral hingga harus ada saat upacara mesabatan biu pada tradisi aci ketiga dalam prosesi seke truna memilih saye dan penampih.

\subsection{Fungsi Simbol Jajan Yang Dibuat Roban Dalam Plaksanaan Tradisi Aci Ketiga}

Membahas fungsi simbol jajan selanjutnya, perlu dikemukakan terlebih dahulu sumber ajaran Agama Hindu. Sumber utama ajaran Agama Hindu adalah Veda. Veda adalah wahyu Tuhan Yang Maha Esa yang di dalam Bahasa Sanskerta disebut Sruti, artinya yang terdengar atau yang didengarkan oleh orang suci.

Pustaka Bhagawata Purana VII.5.23, di dalamnya dinyatakan ada sembilan cara memuja Tuhan yang disebut Nawa Wida Bhakti. Sembilan 
cara itu adalah Sravanam, Kirtanam, Smaranam, Arcanam, Vandanam, Dasyanam, Padasevanam, Sakhyanam dan Atmanivedanam. Sembilan jenis pemujaan inilah umumnya ditradisikan oleh umat Hindu di seluruh dunia dengan wujud budaya yang berbeda-beda.

\subsection{Sebagai Media Pemujaan Terhadap Tuhan}

Umat Hindu di Bali pada umumnya, memuja Hyang Widhi atau Tuhan dalam berbagai manifestasinya. Termuat di dalam teologi Hindu, Tuhan Ajaran Agama Hindu bersumber dari pada pustaka suci Veda yang merupakan wahyu Brahman /Tuhan Yang Maha Esa. Oleh karena bersumber pada sabda suci Tuhan, maka umat Hindu memperoleh ketentraman dan kebahagian hidup yang sejati. Termuat di dalam Manava Dharmawâstra II.10 ditegaskan, bahwa sabda Brahman adalah Veda itu sendiri dan tidak boleh diragukan lagi kebenarannya. Sabda Brahman itu dinyatakan sebagai berikut: śrutis tu vedo vijńeo dharmāsāstram tu vai smrtih te savārthesva mimamsye tabhyām dhārmo hi nirbabhau. Terjemahan Yang dimaksud dengan Śruti adalah Veda. Yang dimaksud dengan Smrti adalah Dharmaúâstra, kedua macam pustaka suci ini tidak boleh diragu-ragukan kebenarannya mengenai apapun juga karena dari keduanya itu hukum (Pudja dan Sudhartha, 2004: 32).

Pemujaan Hyang Widhi dengan menggunakan simbol jajan sebagian besar dapat ditemukan dalam banten untuk kelengkapan upacara. Simbol jajan itu ada pada bagian banten yang dipergunakan sebagai persembahan dan ada pula pada gegantungan yang menghiyasi bale/ bangunan baik pada Pura bale Agung, bale kulkul, bale perantenan, dan bale peyadnya. Menurut Wianawawancara 16Maret2017Simbolatau sering pula disebut niasa merupakan simbol perwujudan Sang Hyang Widhi sebagai widyadara-widyadari. Tuhan Yang Maha Esa atau Brahman adalah tanpa wujud, rohani yang tidak terbatas, berada dalam segala sesuatu dan melampui segala sesuatu. Lebih jauh Wiana mengatakan, salah satu cara pemujaan adalah dengan jalan kebhaktian (Bhakti Yoga). Jalan kebaktian ini yaitu menggunakan sarana simbol, baik mempergunakan jajan atau raka banten, gambar, atau patung (arca) dari wujud yang dipilih. Pemujaan melalui simbol ini adalah antara lain dapat diwujudkan dalam bentuk simbol dalam pengunaan jajan yang terdapat pada banten dan gegantungan. Simbol ini digunakan untuk memudahkan dalam memfokuskan kepada umat yang melaksanakan upacara mesabatan biu dalam Tradisi Aci Ketida melampaui hal-hal material.

Pentingnya wujud Tuhan sebagai media melaksanakan bakti kepada Tuhan dapat disimak pada Bhagavadgita XII.5 sebagai berikut. kleso 'dhikataras tesam avyaktasakta-cetasam, avyakta hi gatir duhkam dehavadbhir avapyat. Terjemahan:

Bagi mereka yang pikirannya terpusatkan kepada yang Tak berwujud, kesulitannya lebih besar, karena sesungguhnya jalan dari Yang Tak termanifestasikan sukar dicapai oleh orang yang mempunyai badan jasmani.

Menyimak sloka di atas, maka selama manusia memiliki badan jasmani atau semasih hidup di dunia ini, maka selalu memerlukan wujud atau simbol dalam melakukan pemujaan. Jelasnya, Bhagavadgita menyatakan, sangat sulit manusia melakukan pemujaan tanpa sifat dan bentuk. Selama manusia masih memiliki keterikatan pada badan kasar dan masih tenggelam dalam kesadaran fisik, maka tidak akan mampu memahami serta mencapai Yang Mahatinggi yang tanpa sifat dan tanpa bentuk atau wujud. Wujud Tuhan dalam berbagai bentuk termasuk penjelmaan dalam wujud awatara, hanya bersifat sementara, sedangkan aspek ketuhanan tanpa wujud bersifat kekal, ada di mana-mana dan tak berubah. Demi kepuasan manusiawi manusia memberikan nama dan wujud kepada Tuhan, tetapi sesungguhnya Ia sama sekali tidak berwujud. Tuhan mengambil suatu wujud sehingga manusia dapat memuja-Nya dan mengagumi-Nya, berbhakti dan mencintaiNya dan dengan demikian memenuhi cita-cita spiritualnya.

Mengutip pendapat Svami Sivananda, dalam Titib (2003:64) mengemukakan, pratima atau patung merupakan pengganti. Gambar atau 
arca pada sebuah pura, walaupun terbuat dari batu, kayu, kertas, atau logam, sangat berharga bagi penyembah, karena hal itu menandakan ada hubungan dengan yang disembah, Tuhan Yang Maha Esa atau manifestasinya. Gambar, arca, atau simbol menggantikan sesuatu yang disucikan dan abadi.

Mengacu pada uraian di atas, maka makna yang terkandung dalam simbol jajan pada upacara mesabatan biu pada tradisi Achi ketiga adalah sebagai berikut.

Simbol-simbol jajan pada upacara mesabatan biu pada tradisi Achi ketiga memiliki sejumlah makna, antara lain makna teologi. Sebelum membahas makna ini, terlebih dahulu dikemukakan pengertian teologi. Kata teologi berasal dari kata theos yang artinya 'Tuhan' dan 'logos' artinya 'ilmu' atau 'pengetahuan'. Mengacu pada pengertian itu, teologi berarti 'pengetahuan tentang Tuhan'. Selain itu teologi secara harfiah juga berarti teori atau studi tentang Tuhan. Ilmu ketuhanan dalam Agama Hindu diberi dengan bermacam-macam istilah antara lain: (1) Brahma Widya; (2) Brahma Tatwa Jnana. Istilah Brahma sering dipergunakan oleh umat Hindu untuk menyebutkan nama Tuhan sebagai pencipta pemelihara maupun tempat tujuan dari manusia atau alam semesta pada zaman pralaya. Menurut Hindu, teologi juga disebut Brahmavidya yang berarti pengetahuan tentang ketuhanan, pengetahuan tertinggi, dan pengetahuan rohani (spiritual). Berdasarkan uraian tersebut brahmavidyà berarti pengetahuan tentang Tuhan Yang Maha Esa, mencakup semua manifestasi-Nya, ciptaan-Nya dan segala sesuatu yang berkaitan dengan-Nya (Titib, 2003:17).

Berdasarkan beberapa pengertian tersebut, makna teologi yang terkandung dalam simbolsimbol jajan pada upacara mesabatan biu pada tradisi Achi ketiga yakni peningkatan srada (keyakinan) terhadap kaagungan atau kemahakuasaan Tuhan. Hal itu dapat diuraikan sebagai berikut. Tentang hakikat Tuhan yang tidak berwujud dalam simbol-simbol jajan pada upacara mesabatan biu pada tradisi Achi ketiga dapat disimak pada istilah raka banten. Kata raka banten berarti atau bermakna widyadara-widyadari, atau gopala-gowinda yang bermakna menghibur dan menggendalikan dalam konteks filsafat disamakan dengan suksma dan sunya (Lanús, 2004).

Karena merupakan simbol maka jajan yang di pergunakan tersebut juga berarti abstrak atau berwujud tidak persis sama pada obyeknya. Sifat Tuhan itu juga dapat disimak dalam Bhagavadgita II-25 yakni sebagai berikut. avyakto 'yam acintyo 'yam avikaryo 'yam ucyate tasmad evam viditvainam nanusocitum arhasi Terjemahan:

Dia tidak dapat diwujudkan dengan katakata, tak dapat dipikirkan dan dinyatakan, tak berubah-ubah; karena itu dengan mengetahui sebagaimana halnya, engaku tak perlu berduka. (Pudja, 2005:47).

Demikian pula dalam Bhagavadgita XII3 dinyatakan sebagai berikut. ye tv aksaram anirdesyam avyaktam paryupasate sarvatragam acintyam ca kuta-stham acalam dhruvam. Terjmahan:

Tetapi mereka yang memuja Yang Kekal Abadi, Yang Tak termuskan Yang Tak nyata, Yang melingkupi segalanya, dan Yang Tak terpikirkan, Yang tak berubah, Yang tak bergerak, Yang abadi (Pudja, 2005:310).

KemudiandalamKitabManawadharmasastra I-3 disebutkan sebagai berikut, tvameko hyasya sarvasya vidanasya svayam bhuvah, acintyasya prameyasya karya tattvarthavit prabho. Terjemahan:

Sesunguhnya hanya Engkau-lah yang maha mengetahui, tentang makna upacara dan Veda yang muncul dengan sendirinya, yang tak kami pahami dan terjamah (Pudja dan Tjokorda Rai Sudharta, 2004:1).

Literatur Hindu mengemukakan, Tuhan bersifat immanent, yakni sifat Tuhan sebagai pencipta alam semesta berserta isinya, berada di luar dan sekaligus di dalam ciptaannya. Hakikat Ketuhanan dalam Veda adalah monotheisme 
transcendent dan monotheisme immanent serta monisme. Pandangan monisme yakni keyakinan terhadap adanya keesaan Tuhan Yang Maha Esa merupakan alam semesta. Tuhan itu Esa dalam segalanya, dan segalanya berada di dalam yang Esa. Hakikat Ketuhanan dalam istilah simbol jajan pada upacara mesabatan biu pada tradisi Achi ketiga menunjukkan bahwa Tuhan tidak memiliki wujud. Hal ini memang sesuai dengan ajaran bahwa Tuhan itu juga bersifat monotheisme immanent, yaitu Tuhan selalu digambarkan sebagai Impersonal God atau Tuhan yang tidak berpribadi (Titib, 2003:32-33).

Tuhan yang Esa ini dipuja orang dengan berbagai cara, di berbagai tempat dan dalam berbagai aspek dan perwujudannya. Dewa-dewa itu adalah aspek dari Yang Esa. Dalam seni budaya Bali, khususnya seni cacalan sering pula disebut Sanghyang dewa-dewi. Prosesi persembahyangan dengan menyembah Sanghyang dewa-dewi ini telah ditampilkan dalam banten bebangkit yang dihaturkan di dalam gedong pura bale agung. Jajan sebagai raka banten simbol dewa-dewi diisi pada banten aturan. Karena itu dalam segi penampilan simbol, terdapat perbedaan yang mencolok antara jajan cacalan satu daerah dengan daerah lainnya. Terlepas dari perbedaan itu, mengamati penggunaan simbol jajan tersebut di atas, maka dapat ditafsirkan, bahwa yang dimaksud dengan dewa-dewi pada raka banten pada kehidupan itu adalah menunggalnya bhakta atau penyembah dengan yang disembah. Maknanya bahwa roban yang membuat jajan tersebut bertujuan untuk keselamatan para seka truna saat melaksanakan upacara mesabatan biu.

Tentang keyakinan terhadap Tuhan, dalam Bhagavdgita IX-3 menyatakan: asraddadhanah purusa dharmasyah-sya paramtapa, aprapya mam nivartante mrtyu-samsara-vartmani. Artinya: Manusia tanpa keimanan, yang mengikuti jalan ini, wahai penaklum musuh (Arjuna), tak mencapai Aku dan kembali ke jalan dunia kematian, menderita. Pudja (2005:224) mengomentari sloka tersebut diatas, bahwa unsur yang terpenting dalam menjalankan keimanan dalam mistik yakni adanya keyakinan. Dasar pengertian ini dijelaskan dalam Yajurveda XIX.30 dalam hubungan konsep dasar antara sraddha, vrata, diksa, dan daksina (pahala spiritual). Kembali ke jalan dunia kematian, menderita, yaitu akan kembali ke dunia ini dalam bentuk inkarnasi (siklus ketidakkekalan dunia). Mereka yang tidak memiliki keyakinan, yang tidak mau menerimanya, tidak akan dapat pembebasan dan kembali lahir ke dunia fana ini. Keyakinan yang diharapkan adalah keyakinan pada realitas kebijaksanaan yang menyelamatkan dan kemampuan manusia untuk mencapainya. Langkah pertama untuk menuju pembebasan Ilahi adalah keyakinan pada ke-Ilahi-an yang ada pada diri manusia tersebut, yang menunjang keberadaan dan kegiatannya. Oleh karena itu, bentuk-bentuk jajan selain bulat/lingkaran, persegi empat dan persegi tiga, ada pula jajan yang menyimbulkan tentang kekayaan alam semesta. Inilah ajaran yang terus-menerus di sampaikan hinga penggunaan simbol jajan tetap lestari karen maknanya yang sangat sakral dan mendalam.

Terlepas dari itu, simbol jajan sebagai raka banten dan hiyasan atau gegantungan yang terdapat pada pelaksaan upacara mesabatan biu pada tradisi aci ketiga memiliki makna, bahwa Tuhan sesungguhnya adalah satu dan merupakan sumber kehidupan. Dengan demikian, maka semua umat manusia memiliki sumber yang satu yakni Tuhan Yang Maha Esa. Hal itu juga memiliki makna, bahwa umat Hindu di Bali yang membagi atau menggolongkan dirinya ke dalam berbagai soroh (klan) pada hakikatnya berasal dari satu sumber atau kawitan, yakni Tuhan Yang Maha Esa. Hal ini mengandung makna, bahwa semua manusia pada hakikatnya adalah bersaudara. Jadi dengan demikian, jika umat Hindu di Bali, digolongkan berdasarkan kasta atau stratifikasi sosial beradasarkan garis keturunan, berdasarkan filsafat Ketuhanan tadi, adalah keliru. Berdasarkan paham tersebutlah maka di Desa Tenganan tidak dikenal dengan lapisan masyarakat atau tidak adanya kasta.

Termuat di dalam Rgveda bahwa semua nama dewa adalah nama Tuhan yang hakikatnya adalah satu. Juga disebutkan, Tuhan mempunyai ribuan nama, tetapi bukan berarti Tuhan lebih dari 
satu.

Taitirya Upanisad 3.1, Varuna ada disebutkan, sang ayah mengajar putranya Bhrgu, tentang pengetahuan suci. Beliau menjelaskan: "Itu sesungguhnya, dari mana makhluk-makhluk ini dilahirkan dan dari mana sejak lahir mereka hidup, dan memasuki apa ketika mereka pergi. Itulah yang ingin diketahui. Itulah Brahman". Batasan dari Brahman sebagai asal, kelanjutan dan peleburan alam datang dari Isvara yaitu Tuhan Pencipta, Pemeliharaan, dan Penghancur. Brahman adalah penyebab alam semesta sebagai substratum (adhisthna), sebagai penyebab material (updan) dari alam, sebagai pula emas adalah bahan penyebab perhiasan emas, sebagai alat penyebab (nimitta) dari dunia, Madva (Radhakrishnan, 1992 :252).

Chandogya Upanisad III.14.1. dinyatakan "Sarwam khalv idam brahma...", "Semua yang ada sesungguhnya Brahman...". Brahman adalah di luar juga di dalam alam semesta dan ada pada semua makhluk. Beliau yang disebut Narayana ada pada yang hidup dan ada pula pada yang fana. Di dalam Kena Upanisad dinyatakan bahwa dewa Agni, dan Vayu tidak dapat beraktivitas tanpa Brahman. Para dewa itu mendapatkan kuasa mereka untuk membakar segala sesuatu dari Brahman. Dengan demikian Brahman adalah tokoh dewa, sekaligus pula sebagai dewa yang tertinggi.

Brahman dapat dinyatakan dengan ungkapan sat-cit ananda. Kata sat berarti ada atau keberadaan. Jika Brahman disebut sat berarti bahwa hanya Brahman-lah yang memiliki keberadaan. Brahman-lah satu-satunya yang ada, yang harus dibedakan dengan segala yang lain dari pada-Nya, yang tidak memiliki ada atau keberadaan. Kata cit berarti kesadaran yang menunjuk kepada sifat Brahman yang rohani. Ananda artinya bahagia, yang menunjuk kepada sifat Brahman yang meliputi segala sesuatu dan mempersatukan segalanya yang hanya terdiri dari kebahagiaan saja. Ungkapan sat-cit-ananda menunjukkan bahwa Brahmanlah satu-satunya realitas rohani yang bersifat mutlak, tetapi juga meliputi segala sesuatu yang ada, yang sadar atau yang bersifat rohani, sehingga segala sesuatu yang memiliki kedua sifat itu harus dialirkan ke luar dari pada-Nya.

Upanisad menyatakan bahwa Tuhan pada hakikatnya Esa, sumber segala sesuatu yang ada di Alam Semesta dan menjadi tempat kembalinya segala sesuatu. Beliau Pencipta, Pengatur sekaligus sebagai Pemralina segala sesuatu yang ada di Alam Semesta ini, dalam pernyataan tersebut terdapat konsep Ketuhanan yang bersifat monotheisme transendent dan immanent. Sebuah kalimat dalam Brhadranyaka Upanisad menyatakan : "Sarwam Khalvidam Brahman" 'Segalanya adalah Tuhan Yang maha Esa'. Konsep ini mengandung paham Monisme. Keyakinan terhadap adanya Keesaan Tuhan yang merupakan hakikat alam semesta. Esa dalam segalanya. Segalanya berada di dalam yang Esa.

Menyimak sloka-sloka di dalam kitab suci, maka dengan tegas disebutkan bahwa Tuhan berada dalam semua makhluk. Dengan kata lain, Tuhan merupakan jiwa semua makhluk. Tuhan-lah yang menghidupi semua makhluk dan meresapi yang ada di dunia. Tuhan adalah Atman, atau identik dengan Atman yang menghidupi semua makhluk. Kata Atman, diambil dari kata An (bernafas), yaitu nafas kehidupan (Maswinara 1996 :75). Atman merupakan prinsip kehidupan manusia, roh yang meresapi, atau meliputi keberadaannya, nafas (prana), kecerdasan (prajna) dan mengatasinnya, untuk mengetahui lebih jauh hubungan Atma dengan Brahma, dapat dilihat dari petikan mantra berikut ini: Eko vasti sarvabhutantaratma ekam bijam bahudha yah karoti tam atmasyham ye'nupasyanti dhiras tesyam sukham sasvatam netaresam

(Katha Upanisad

Bag II:12) Artinya; Dia yang tunggal itulah penguasa semuanya atma yang esa itu menjadikan dirinya tampak jamak ia yang arif menyadari dia bersemayam dalam jiwa memperoleh sukacita kekekalan, bukan yang lainnya. Sarvam hy etad brahma ayam Atma Brahma so'yam Atma catuspat (Mandukya upanisad :2) Artinya: Semua ini adalah Brahman Atman adalah Brahman Atman, sang diri, memiliki empat kaki. 


\section{Simpulan Dan Saran-Saran}

\subsection{Simpulan}

Berdasarkan pembahasan pada bab-bab terdahulu sesuai dengan permasalahan yang diajukan, maka ada beberapa kesimpulan yang diperoleh yaitu sebagai berikut.

Pertama, bentuk-bentuk simbol-simbol jajan pada upacara mesabatan biu dalam pelaksanaan tradisi aci ketiga ada berupa seni cecacalan, yang ditampilkan dalam bentuk jaja cecacalan tersebut antara lain ada pada banten bebangkit. Simbolsimbol jajan pada upacara mesabatan biu dalam pelaksanaan tradisi aci ketiga juga ada berbentuk seni-seni jaja gegantungan. Seni jaja gegantungan ini, antara lain terdapat pada jaja begina, satuh, dodol, gegorengan.

Kedua, fungsi simbol-simbol jajan pada upacara mesabatan biu dalam pelaksanaan tradisi aci ketiga bagi umat Hindu di Bali, yakni (1) sebagai media pemujaan terhadap Tuhan; (2) sebagai raka banten dalam membuat banten untuk persembahan pada bangunan suci dengan berbagai macam upakara yadnya dan (3) sebagai gegantungan atau hiyasan. Hal itu dapat diuraikan, bahwa simbol-simbol jajan sebagai media pemujaan terhadap Tuhan, dipasang pada banten bebangkit. Kemudian simbol-simbol jajan pada upacara mesabatan biu dalam pelaksanaan tradisi aci ketiga digunakan jajan cacalan dan jajan gegantungan dan jajan sebagai raka banten yang dimaksud di sini adalah jajan yang dirangkai di dalam banten bebangkit, dipasangkan pula pada banten aturan, dan dipergunakan sebagai jajan gegantungan. Fungsi simbol jajan cacalan, jajan gegangtungan, dan jajan raka banten.

Ketiga, makna simbol-simbol jajan dalam upacara mesabatan biu dalam pelaksanaan tradisi Aci ketiga yakni makna teologi, makna keyakinan tetang kemahakuasaan Tuhan, keyakinan tentang keesaan Tuhan, dan makna bahwa semua yang ada adalah satu sumber. Makna teologi bisa diuraikan, bahwa umat diberi keyakinan tentang pengetahuan ketuhanan. Tuhan bisa bersifat abstrak dan juga bisa diwujudkan dalam berbagai bentuk. Simbolsimbol jajan raka banten dan jajan gegantungan/ hiyasan juga memiliki makna bahwa Tuhan Maha Esa, Maha Tunggal, dan tidak ada duanya. Hanya orang bijaksana menyebut dengan nama banyak. Oleh karena Tuhan hanya satu, maka Tuhan juga disebut sebagai sumber dari segala sumber. Semua yang ada bersumber dari Tuhan. Demikian pula semua makhluk hidup termasuk manusia memiliki satu sumber yang dalam bahasa Bali disebut kawitan. Oleh karena itu, di hadapan Tuhan, tidak ada kasta atau tinggi rendahnya derajat manusia berdasarkan kelahiran atau keturunan.

\subsection{Saran-saran}

1. Kepada umat Hindu disarankan agar lebih mengenal dan memahami simbolsimbol jajan sebagai raka banten jajan sebagai gegantungan/hiyasan dalam berbagai bentuk, fungsi, dan maknanya. Pengetahuan tentang hal itu diperlukan untuk mempertebal kepercayaan atau srada kepada Tuhan, sehingga bisa meningkatkan kualitas kehidupan, baik kehidupan pribadi, keluarga, bermasyarakat maupun pergaulan yang lebih luas.

2. Kepada Pemerintah, terutama Pemerintah Daerah yang lebih memahami penduduknya yang beragama Hindu, agar lebih meningkatkan volume upaya pencerahan kepada masyarakat melalui penyuluhanpenyuluhan spiritual. Pemerintah bisa merangkul berbagai lembaga keagamaan yang berbasis Veda untuk melakukan penyuluhan tentang teologi kepada masyarakat.

3. Kepada para peneliti, diharapkan melakukan penelitian lanjutan terhadap aspek-aspek lain yang belum terkaji dalam penelitian ini. Dengan semakin banyaknya hasil penelitian tentang simbol-simbol jajan sebagai raka banten dan sebagai gegantungan/hiyasan, maka akan semakin banyak pula literatur tentang simbol-simbol yang dimiliki Agama Hindu yang ada di Bali. Sehingga dengan demikian, maka hal itu akan menambah wawasan umat Hindu tentang simbol-simbol 
agama dan teologi Hindu dalam rangka pendakian spiritual.

\section{DAFTAR PUSTAKA}

Anonim, 2017. http://mataram351.wordpress. com/agama-dan-kebudayaan-hindu-budha/

Anonim, 2017. "Sejarah Hari Raya Hindu. (Online). http://sejarahharirayahindu. blogspot.com/2017/02/acintya.html. Diakses 17 Juli 2017.

Anonim, 2017. "Sang Hyang Widhi” (Online). https://id.wikipedia.org/wiki/Sang_Hyang_ Widhi. Dikases 12 Juli 2017.

Anonim, 2017. "Pengaruh Perkembangan Agama" (Online). http://e-learningman1mdn. blogspot.com/2017/06/pengaruhperkembangan-agama-dan.html. Dikases 12 Juli 2017.

Anonim, 2017. "Bali”. http://www.voyagevirtuel. com/images/bali_map.jpg, diakses 15 Februari 2017.

Anonim, 2017. "Simbol" dalam http:// id.wikipedia.org/wik . Diakses 12 Juli 2015.

Astra, I Gde. Semadi, Aron Meko Mete, Ida Bagus Puja Astawa, I Nyoman Darma Putra, 2003, "Guratan Budaya dalam Persepektif Multi Kultural”, Denpasar : Kerja sama Program Studi Magister dan Doktor Kajian Budaya, Linguistik, dan Jurusan Antropologi, Fakultas Sastra dan Budaya Universitas Udayana, dan CV Bali Media.

Bessie, Stefanus, 2007.’Pelayanan bagi Lanjut Usia di Panti Sosial Tresna Werdha Wana Seraya Denpasar: Perspektif Kajian Budaya. Tesis, tak diterbitkan. Program Pascasarjana Universitas Udayana Denpasar.

Bungin, Burhan (Ed.).2006.Metodologi Penelitian Kualitatif: Aktualisasi Metodologis Ke Arah Ragam Varian Kontemporer.Jakarta: PT RajaGrafindo Persada.

Bungin, Burhan, 2005. Analisis Data Penelitian Kualitatif Pemahaman Filosofis dan
Metodologis Ke arah Penguasaan Model Aplikasi. Jakarta: PT Raja Grafindo Persada.

Dawson Christoper . 1948. Religion and Culture, London : Sheed \& Ward.

Dimyati, Mudjiono. 2006. Belajar dan Pembelajaran. Jakarta: Penerbit Rineka. Cipta.

Gniastrasakti, 2015. “Gambar Rajah”. (Online) http://gniastra.blogspot.com/p/gambar-rajah. html. Diakses 25 Juli 2015.

Hamidi, 2007. Metode Penelitian dan Teori Komunikasi. Malang: UMM Pres.

Indriastuti, 2015. "Religi dan Seni Masa Prasejarah Kajian di Situs-Situs Megalitik Pasemah". Situs Resmi Balai Arkeologi Palembang. www.arkeologi.palembang.go.id. Dikases 12 Juli 2015.

Johnson, Doyle Paul. 1986, Sociological Theory Classical Founders and Contemporary Perspectives, (diterjemahkan oleh Robert M.Z. Lawang) Jakarta: Gramedia.

Kasturi, N. 1998. Pesan-Pesan Upanisad. Surabaya : Paramita.

Koentjaraningrat, 1980. Beberapa Pokok Antropologi Sosial. Jakarta: Dian Rakyat.

Lanús, Sugi, 2004. "Amor ring Acinya” (online) https://budaya.wordpress.com/2014/05/26/ amor-ring-acintya/. Diakses 1 Juli 2015.

Maswinara, I Wayan, 1996. Konsep Panca Sradha. Surabaya : Paramita.

Mudita, 2010. "Teologi Hindu”. (Online). http:// manyul83.blogspot.com/2010/12/teologihindu_15.html. Diakses 15 Juli 2017.

Mulyana, Deddy, 2000, dalam http://2frameit. blogspot.c

Mulyana, Deddy. 2004. Komunikasi Populer. Bandung: Pustaka Bani Quraisy.

Mulyono, Sri, 1979. Simbolisme dan Mistikisme Dalam Wayang: Sebuah Tinjauan Filosofis. Jakarta: Gunung Agung.

Patilima, Hamid, 2005. Metode Penelitian 
Kualitatif. Bandung: Alfabeta.

Pudja, G. 2005:. Bhagavadgita. Surabaya: Paramita.

Pudja, I Gede, 1999. Theologi Hindu (Brahma Widya). Surabaya : Paramita.

Pudja,G. dan Tjokorda Rai Sudharta, 2004. Manava Dharmasastra (Manu Dharmasastra) atau Weda Smrti Compendium Hukum Hindu. Surabaya:Paramita.

Purnami, Nyoman, 2017,'Konsep Ketuhanan Dalam-Agama Hindu. (Onine).http:// mangpur.blogspot.com/2012/02/konsepketuhanan-dalam-agama-hindu.html. Diakses 12 Juni 2017.

Radhakrishnan, S., Allen George dan Unwin LTD. 1953. Upanisad Utama I dan II. Jakarta : Yayasan Dharma Sarathi.

Sivananda, Sri Swami.2003. Intisari Ajaran Hindu. alih bahasa Yayasan Tim Penerjemah Yayasan Sanatana Dharmasrama. Surabaya: Paramita.

Sobur, Alex.2004. Semiotika Komunikasi. Bandung: PT Remaja Rosda Karya.

Subagyo, P. Joko, 2004. Metode Penelitian dalam Teori dan Praktek. Jakarta: Rineka Cipta.

Sudiatmika, Wayan Adi, 2014. "Patung Dalam Agama Hindu-1". (Online) https://panbelog. wordpress.com/author/adisudiatmika08/ page/48. Diakses 15 Juli 2015.

Sugiarto, R. dan Pudja, G. 1982. Swetaswatara Upanisad. Jakarta : Proyek Pengadaan Kitab Suci Hindu Departemen Agama RI.

Sura, I Gede dan Musna I Wayan. 1993. Materi Pokok Weda. Jakarta : Direktoral Jenderal Bimbingan Masyarakat Hindu dan Budha dan Universitas Terbuka.

Tim Penyusun Kamus Pusat Pembinaan dan Pengembangan Bahasa, 1999. Kamus Besar Bahasa Indonesia. Jakarta: Departemen Pendidikan Nasional-Balai Pustaka.

Titib, I Made, 2003. Teologi \& Simbol-Simbol dalam Agama Hindu. Jakarta: Badan Litbang
Parisada Hindu Dharma Indonesia PusatParamita.

Watra, I Wayan, 2008. Ulap-ulap dan Rerajahan dalam agama Hindu. Surabaya: Paramita.

Wikipedia, 2017.. “Agama”. (Online) dalam http://id.wikipedia.org/wiki/Agama. Diakses 23 Juli 2017. 